\title{
Influencing factors on cardiac structure and function beyond glycemic control in patients with type 2 diabetes mellitus
}

Ryoko Ichikawa ${ }^{1}$, Masao Daimon ${ }^{\text {* }}$, Tetsuro Miyazaki ${ }^{1}$, Takayuki Kawata', Sakiko Miyazaki ${ }^{1}$, Masaki Maruyama', Shuo-Ju Chiang ${ }^{1}$, Hiromasa Suzuki ${ }^{1}$, Chiharu Ito², Fumihiko Sato ${ }^{2}$, Hirotaka Watada ${ }^{2}$ and Hiroyuki Daida ${ }^{1}$

\begin{abstract}
Background: We hypothesized that clinical factors other than glycemic control may influence abnormal cardiac function in patients with type 2 diabetes mellitus (T2DM). We aimed to investigate the independent factors for abnormal cardiac function among clinical factors in T2DM.

Methods: We studied 148 asymptomatic patients with T2DM without overt heart disease. Echocardiographic findings were compared between diabetic patients and 68 age-matched healthy subjects. Early (E) and late (A) diastolic mitral flow velocity and early diastolic mitral annular velocity (e') were measured for assessing left ventricular (LV) diastolic function. We evaluated insulin resistance, non-esterified fatty acid, high-sensitive CRP, estimated glomerular filtration rate, waist/hip ratio, abdominal visceral adipose tissue (VAT), subcutaneous adipose tissue (SAT) and other clinical characteristics in addition to glycemic control. VAT and SAT were quantified by computed tomography.

Results: In T2DM, E/A and e' were significantly lower, and E/e', left atrial volume and LV mass were significantly greater than in control subjects. In multivariate liner regression analysis, VAT was an independent determinant of left atrial volume ( $\beta=0.203, p=0.011), E / A(\beta=-0.208, p=0.002), e^{\prime}(\beta=-0.354, p<0.001)$ and $E / e^{\prime}(\beta=0.220, p=0.003)$. Age was also an independent determinant, whereas fasting plasma glucose and hemoglobin A1c levels were not. In addition to systolic blood pressure, waist-hip ratio $(\beta=0.173, p=0.024)$ and VAT/SAT ratio $(\beta=0.162, p=0.049)$ were independent determinants of LV mass.
\end{abstract}

Conclusion: Excessive visceral fat accompanied by adipocyte dysfunction may play a greater role than glycemic control in the development of diastolic dysfunction and LV hypertrophy in T2DM.

Keywords: Diabetes mellitus, Echocardiography, Cardiac function

Diabetes mellitus may cause myocardial injury even in the absence of coronary artery disease, hypertension or valvular disease [1]. This cardiac dysfunction increases the risk of heart failure and subsequent mortality independently of underlying coronary artery disease and other cardiovascular risk factors [2-4]. Although the mechanisms of myocardial injury in diabetes mellitus are complex, several studies have identified diastolic dysfunction and left ventricular (LV) hypertrophy as major

\footnotetext{
* Correspondence: masaodaimon@gmail.com

${ }^{1}$ Department of Cardiovascular Medicine, Juntendo University School of Medicine, Tokyo, Japan

Full list of author information is available at the end of the article
}

characteristics of abnormal cardiac function and structure in diabetes mellitus using echocardiography, even in the absence of hypertension [5-8], Using animal models, many previous investigations have documented possible mechanisms underlying myocardial injury in diabetic mellitus [1,9]. However, the pathophysiology of diabetic myocardial injury has been still unclear in the clinical setting. Not only glycemic control, but many other factors including hyperinsulinemia [10], increased fatty acids [11], inflammation [12], renal function [13] and myocardial steatosis [14] have been postulated to contribute to the development of abnormal function and structure in diabetic mellitus. Nevertheless, the independent 
influence of these factors on cardiac functional parameters beyond glycemic control has not been adequately evaluated in humans. In addition, few studies [15-17] have included a control group, and comparison with age-matched controls is essential to evaluate LV diastolic dysfunction and hypertrophy because even healthy subjects $>60$ years old may have significant diastolic dysfunction $[18,19]$.

Recently, visceral fat accumulation has gained attention as playing an important role in the development and pathophysiology of type 2 diabetes mellitus (T2DM) $[20,21]$. Excessive visceral fat is closely associated with adipocyte dysfunction accompanied by increased inflammatory cytokine secretion and reduced anti-inflammatory adiponectin secretion, which can lead to cardiac and endothelial dysfunction [22-24]. Thus, we hypothesized that visceral fat accumulation may be associated with abnormal cardiac function and structure in T2DM.

The aims of our study were the following: (1) to clarify if diastolic dysfunction and LV hypertrophy are characteristics of abnormal cardiac function and structure in T2DM in comparison with age-matched healthy controls; and (2) to investigate the independent factors for diastolic dysfunction and LV hypertrophy among clinical factors including glycemic control, blood pressure, insulin resistance, fatty acid and visceral fat.

\section{Methods}

\section{Study population}

A total of 148 consecutive asymptomatic patients with T2DM and without cardiovascular disease, who were admitted to our institution (Juntendo University Hospital Tokyo, Japan) for diabetic educational program between January 2010 and May 2012, were prospectively enrolled in this study. Patients were included if they met the following inclusion criteria: no symptoms and history of heart disease, LV ejection fraction (LVEF) $>50 \%$, absence of regional LV wall motion abnormalities, and clinically stable. Exclusion criteria were coronary artery disease, congenital heart disease, atrial fibrillation, significant heart valve disease, renal failure (serum creatinine $>2.0 \mathrm{mg} / \mathrm{dl}$ ) and type 1 diabetes mellitus. In addition, 68 age-matched healthy controls without hypertension, dyslipidemia or diabetes mellitus served as a control group. The study protocol was approved by the Institutional Review Board of Juntendo University Hospital.

\section{Clinical data and echocardiographic measurements}

This study was a prospective cohort study. The diagnoses of hypertension, dyslipidemia, coronary artery disease and cerebrovascular accident were assessed by the treating physician. Standard comprehensive twodimensional and Doppler echocardiographic examinations were performed using commercially available systems. As indicators of obesity, body mass index was calculated from height and weight and the waist-hip ratio was calculated from the waist and hip circumference.

\section{Conventional, 2D and Doppler echocardiography}

In all patients and control subjects, cardiac chamber quantification by $2 \mathrm{D}$ echocardiography was performed according to guidelines provided by the American Society of Echocardiography [25]. LV diameters were measured using 2D echocardiography according to the recommended criteria. The thickness of the intraventricular septum and the LV posterior wall were measured at end-diastole. LV mass was calculated using diastolic measurements of LV diameter and wall thickness on 2D echocardiography according to the formula recommended by the American Society of Echocardiography [25]. LV end-diastolic volume and endsystolic volume were determined from the apical views using modified biplane Simpson's method. LV ejection fraction was calculated by the following equation: $100 \times$ (enddiastolic volume - end-systolic volume)/end-diastolic volume. Each parameter was indexed for body surface area (BSA), when appropriate.

For assessing conventional diastolic parameters, left atrial volume was measured by Simpson's biplane method (indexed to body surface area), and mitral inflow velocities were determined by pulsed Doppler and tissue Doppler imaging. The peak early (E) and late (A) diastolic velocity, the deceleration time from the peak of the early diastolic wave to baseline (DCT) and the E/A ratio were assessed from the mitral inflow velocity pattern. The mitral annular motion velocity was recorded at the medial mitral annulus site in the apical 4-chamber view by pulsed tissue Doppler echocardiography. Peak early (e') and late (a') diastolic velocity of the annulus were measured and the ratio of peak early diastolic transmitral flow velocity to annular velocity (E/e') was calculated [26]. Furthermore, according to previous reports [26,27], we classified diastolic function in all subjects into one of four categories (normal, grade I, grade II or grade III) to compare the prevalence of diastolic dysfunction between healthy subjects and diabetic patients.

\section{Laboratory measurements}

Blood samples for determination of serum creatinine, fasting blood sugar, glycosylated hemoglobin, immunoreactive insulin, $\mathrm{C}$-peptide immunoreactivity, $\mathrm{N}$-terminal pro B-type natriuretic peptide (NT-pro BNP) and lipid profiles (triglycerides, high-density lipoprotein cholesterol and low-density lipoprotein cholesterol) were drawn in patients with T2DM. Moreover, the homeostasis model assessment ratio (HOMA-R) index was calculated as fasting plasma glucose $\times$ fasting plasma insulin/22.5 for assessing insulin resistance [28]. Non-esterified fatty acid (NEFA) was measured since it has been suggested to play a critical role 
in triggering the development of cellular insulin resistance and myocardial contractile dysfunction [11]. In addition, high-sensitive C-reactive protein (hsCRP) was measured as a marker of inflammation. Estimated glomerular filtration rate (eGFR) was determined based on the new Japanese coefficient-modified Modification of Diet in Renal Disease (MDRD) study equation [29]. The formula is as follows: $\mathrm{eGFR}=194 \times$ serum creatinine $(\mathrm{SCr})^{-1.094} \times$ age-0.287, where age is in years, $\mathrm{SCr}$ is in $\mathrm{mg} / \mathrm{dL}$ and GFR is in $\mathrm{mL} /$ $\min / 1.73 \mathrm{~m}^{2}$ body surface area. The product of this equation was multiplied by a correction factor of 0.739 in women.

\section{Abdominal fat area}

VAT and subcutaneous adipose tissue (SAT) were measured quantitatively by computed tomography (CT) (Aquilion64, Toshiba, Tokyo, Japan), as previously reported [30]. Briefly, an axial CT scan at the level of the umbilicus was obtained for each participant using an electron beam CT scanner (commercial available software). Planimetric measurements at the level of the umbilicus have been shown to correlate well with volumetric quantification of VAT $(r=0.81$ in men and $\mathrm{r}=0.85$ in women, $\mathrm{p}<0.001)$ and SAT $(\mathrm{r}=0.95$ in men and $\mathrm{r}=0.85$ in women, $\mathrm{p}<0.001$ ) [30]. The images generated were transferred to a workstation and analyzed using commercial software. The coefficients of variation between two observers analyzing the same VAT and SAT images $(n=30)$ ranged from $0.6 \%$ to $14.2 \%$ and from $0.1 \%$ to $7.3 \%$, respectively. Both VAT and SAT was indexed for body surface area as well as echocardiographic parameters.

\section{Statistical analysis}

All statistical analyses were performed using SPSS version 17.0 (SPSS, Inc., Chicago, IL). Data are expressed as mean \pm standard deviation (SD). The relationships between variables were assessed using Pearson's correlation coefficient. We compared baseline characteristics and echo parameters between the control group and patients with T2DM using an unpaired t-test. Categorical data were compared between the two groups using a chi-square test. When we found echocardiographic parameters that were different between the diabetics and controls, Pearson's linear correlation analysis was used to determine the correlations between these echocardiographic parameters and the clinical data in just the patients with T2DM. Multiple linear regression analysis was also performed using the clinical data to evaluate the independent determinants of these echocardiographic parameters in the T2DM patients. A logtransformation was used to normalize the distributions of triglyceride, HOMA-R and NT-proBNP level. A $\mathrm{P}$-value $<.05$ was considered statistically significant.

\section{Results}

Table 1 shows the baseline characteristics of the study population. The study population consisted of 68 healthy controls and 148 patients with T2DM (total, 216). In patients with T2DM, body surface area, body mass index, blood pressure and heart rate were significantly higher than in normal controls. In the group with T2DM, $48 \%$ had hypertension and $63 \%$ had dyslipidemia.

\section{Comparison of echocardiographic parameters between the two groups}

Table 2 shows differences in echocardiography parameters between the two groups. Patients with T2DM had a greater LV mass index than normal controls. LV mass index of control subjects, diabetic patients without hypertension, and diabetic patients with hypertension, were $70 \pm 12$, $79 \pm 18$, and $83 \pm 22 \mathrm{~g} / \mathrm{m}^{2}$, respectively. LV mass index of both diabetic patients with and without hypertension were increased as compared with control subjects $(\mathrm{p}<0.01$ and $\mathrm{p}<0.001$, respectively) as shown in previous studies [5-8]. Patients with T2DM also had a significantly larger left atrial volume index, lower e' and E/A, and higher E/e', indicating LV diastolic dysfunction, as previously reported [5-8]. Whereas $23 \%$ of the age-matched healthy controls had diastolic dysfunction with advancing age, $56 \%$ of patients with T2DM had diastolic dysfunction, indicating a higher prevalence of diastolic dysfunction in the diabetic population (Figure 1). None of the subjects were classified into grade III diastolic dysfunction.

\section{Determinants of the abnormal echocardiographic parameters in T2DM}

Laboratory data and visceral fat area measured by CT scanning are shown in Table 3. Among the clinical factors in Tables 1 and 3, we determined which factors were associated with the abnormal echocardiographic parameters shown in Table 2. The LV mass index had a significant correlation with systolic blood pressure, waist/hip ratio, low-density cholesterol level and VAT/ SAT ratio (Table 4). Multivariate liner regression analysis found that systolic blood pressure, waist/hip ratio and VAT/SAT ratio were independent factors associated with LV mass index (Table 5).

The correlation between clinical factors and the diastolic parameters are also shown in Table 4. These diastolic parameters were mainly correlated with gender, age, hypertension and VAT, whereas E/A and e' were also correlated with decreased eGFR. In multivariate linear regression analysis, age was the strongest independent determinant of left atrial volume, E/A, e' and E/e' among all the clinical variables. Furthermore, VAT was also an independent determinant of these four diastolic parameters (Table 5, Figure 2), indicating excess VAT may be independently associated with diastolic 
Table 1 Baseline characteristics of the study population

\begin{tabular}{|c|c|c|c|}
\hline Variable & $\begin{array}{l}\text { Controls } \\
(n=68)\end{array}$ & $\begin{array}{l}\text { Patients with } \\
\text { T2DM }(n=148)\end{array}$ & $p$ value \\
\hline \multicolumn{4}{|l|}{ Demographics } \\
\hline Age, year & $56 \pm 11$ & $58 \pm 12$ & 0.16 \\
\hline Men/Women & $45 / 23$ & $95 / 53$ & 0.72 \\
\hline Systolic BP, mm Hg & $118 \pm 11$ & $126 \pm 17$ & $<0.001$ \\
\hline Diastolic BP, mm Hg & $71 \pm 7$ & $68 \pm 10$ & $<0.001$ \\
\hline Heart rate, bpm & $62 \pm 9$ & $71 \pm 10$ & $<0.001$ \\
\hline Body mass index, $\mathrm{kg} / \mathrm{m}^{2}$ & $22.6 \pm 2.6$ & $26.1 \pm 5.5$ & $<0.001$ \\
\hline Body surface area, $\mathrm{m}^{2}$ & $1.66 \pm 0.16$ & $1.76 \pm 0.38$ & 0.002 \\
\hline Disease duration, months & 0 & $121 \pm 93$ & \\
\hline Waist/Hip ratio & - & $0.89 \pm 0.20$ & \\
\hline \multicolumn{4}{|l|}{ Comorbidity } \\
\hline Hypertension, n (\%) & 0 & $71(48 \%)$ & \\
\hline Dyslipidemia, n (\%) & 0 & $93(63 \%)$ & \\
\hline Cerebral vascular disease, n (\%) & 0 & $9(6 \%)$ & \\
\hline ASO, n (\%) & 0 & $4(3 \%)$ & \\
\hline Smoking, n (\%) & - & $68(46 \%)$ & \\
\hline Medications & 0 & $101(68 \%)$ & \\
\hline Sulfonylureas, n (\%) & 0 & $57(38 \%)$ & \\
\hline Biguanide, n (\%) & 0 & $56(38 \%)$ & \\
\hline a-glucocitase inhibitor, n (\%) & 0 & $37(25 \%)$ & \\
\hline Pioglitazone, n (\%) & 0 & $22(15 \%)$ & \\
\hline Insulin, n (\%) & 0 & $45(30 \%)$ & \\
\hline DPP-4 inhibitor, n (\%) & 0 & $21(14 \%)$ & \\
\hline GLP-1 analog, $n$ (\%) & 0 & $4(3 \%)$ & \\
\hline
\end{tabular}

$B P$, blood pressure; $A S O$, atherosclerotic obliterance; DPP-4, Dipeptidyl peptidase-4.

Data are expressed as mean \pm SD it as number (percentage).

dysfunction in T2DM. As for e' and E/e', female gender and hypertension were independent determinants. Furthermore, there were positive correlations between VAT and $\log$ triglyceride $(\mathrm{r}=0.376, p<0.001)$, IRI $(\mathrm{r}=0.393$, $p<0.001)$ and $\log$ HOMA-R $(\mathrm{r}=0.363, p<0.001)$.

\section{Discussion}

In the current study, we found that LV diastolic dysfunction and hypertrophy were more prominent in patients with T2DM than in age-matched healthy controls, as previously reported [5-8]. Furthermore, we identified the independent factors associated with LV diastolic dysfunction and hypertrophy. Gender, age, hypertension and VAT were all independently associated with diastolic dysfunction, and the waist/hip and VAT/SAT ratios were independently associated with increased LV mass, in addition to systolic blood pressure. Of note, our study is the first to show that excess VAT is more important than glycemic control, insulin resistance, renal function and
Table 2 Comparison of echocardiographic parameters between normal controls and patients with T2DM

\begin{tabular}{lccc}
\hline & $\begin{array}{c}\text { Controls } \\
(\mathbf{n}=\mathbf{6 8})\end{array}$ & $\begin{array}{c}\text { Patients } \text { with } \\
\text { T2DM }(\mathbf{n}=\mathbf{1 4 8})\end{array}$ & $\boldsymbol{p}$ value \\
\hline LV Mass index, $\mathrm{g} / \mathrm{m}^{2}$ & $70 \pm 12$ & $81 \pm 20$ & $<0.001$ \\
LVEDV index, $\mathrm{ml} / \mathrm{m}^{2}$ & $49 \pm 12$ & $51 \pm 12$ & 0.155 \\
LVESV index, $\mathrm{ml} / \mathrm{m}^{2}$ & $17 \pm 4.8$ & $17 \pm 5.0$ & 0.450 \\
LV ejection fraction, \% & $64 \pm 5$ & $68 \pm 5$ & $<0.001$ \\
LA volume index, $\mathrm{ml} / \mathrm{m}^{2}$ & $22 \pm 8$ & $24 \pm 8$ & 0.041 \\
E/A ratio & $1.1 \pm 0.4$ & $0.9 \pm 0.3$ & $<0.001$ \\
DCT time, msec & $205 \pm 46$ & $206 \pm 48$ & 0.924 \\
$\mathrm{e}^{\prime}, \mathrm{cm} / \mathrm{sec}$ & $8.2 \pm 2.5$ & $6.5 \pm 1.8$ & $<0.001$ \\
$\mathrm{a}^{\prime}, \mathrm{cm} / \mathrm{sec}$ & $9.4 \pm 1.9$ & $6.4 \pm 1.8$ & 0.783 \\
E/e ratio & $8.3 \pm 2.1$ & $9.7 \pm 3.3$ & 0.001 \\
\hline
\end{tabular}

LVEDV, left ventricular end-diastolic volume; $L V E S V$, left ventricular end-systolic volume; $L A$, left atrial.

other clinical factors in abnormal cardiac structure and function in T2DM.

Many previous studies have demonstrated a high prevalence of LV diastolic dysfunction and hypertrophy in patients with T2DM [5-8]. However, few studies have included a control group [15-17]. Diastolic dysfunction progresses with age even in a healthy population, and diastolic dysfunction is a common phenomenon in healthy individuals over 60 years old $[18,19]$. Thus, it is important to compare diabetics with age-matched control subjects when evaluating the prevalence of diastolic dysfunction. In this study, a higher prevalence of diastolic dysfunction, in addition to increased LV mass, was found in T2DM compared with control subjects. The $23 \%$ prevalence of diastolic dysfunction in the control subjects was probably due to aging.

Myocardial injury in T2DM has a complicated pathophysiology [1,9], and many factors, such as hyperinsulinemia [10], increased fatty acid [11], inflammation [12], renal function [13] and myocardial steatosis [14], have been postulated to be involved in its development. However, most previous clinical studies of diabetic cardiac dysfunction examined only glycemic control and other common cardiovascular risk factors, such as hypertension or obesity [5-8,15-17]. Furthermore, some recent review articles that performed meta-analysis of multiple trials reported that intensive glycemic control does not inevitably result in a reduction of cardiovascular events and mortality [31,32]. Thus, we hypothesized that some factors other than glycemic control may play an important role in the development of abnormal cardiac structure and function in T2DM. In this study, we investigated the association between echocardiographic 


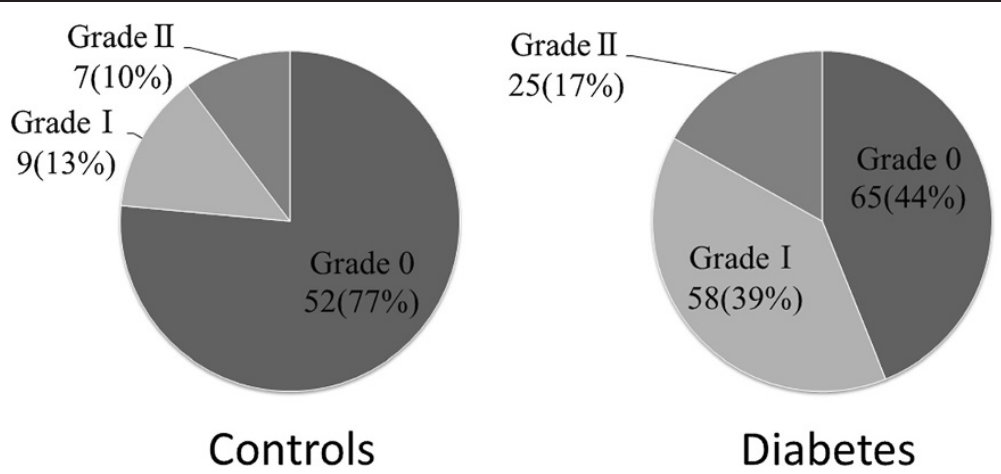

Figure 1 Distribution of diastolic dysfunction in age-matched healthy subjects and patients with T2DM.

parameters in T2DM and several common risk factors, as well as factors that have not been examined before in the clinical setting. Importantly, excess VAT in our study, but not glycemic control, was found to be independently associated with diabetic diastolic dysfunction, in addition to gender, age and hypertension. Visceral fat accumulation might be a potential therapeutic target to improve cardiac dysfunction in T2DM rather than glycemic control.

Table 3 Laboratory data and adipose tissue area with computed tomography in patients with T2DM

\begin{tabular}{|c|c|}
\hline & Patients with T2DM $(\mathrm{N}=148)$ \\
\hline \multicolumn{2}{|l|}{ Laboratory data } \\
\hline Creatinine, mg/dl & $0.92 \pm 0.17$ \\
\hline $\mathrm{eGFR}, \mathrm{ml} / \mathrm{min}$ & $83 \pm 26$ \\
\hline Triglyceride, mg/dl & $139 \pm 100$ \\
\hline HDL cholesterol, mg/dl & $50 \pm 15$ \\
\hline Total cholesterol, mg/dl & $198 \pm 34$ \\
\hline F-LDL cholesterol, mg/dl & $119 \pm 32$ \\
\hline Fasting plasma glucose, mg/dl & $138 \pm 38$ \\
\hline Hemoglobin A1C, \% & $7.9 \pm 1.4$ \\
\hline NEFA, $\mu E q / L$ & $613 \pm 202$ \\
\hline $\mid \mathrm{RI}, \mu \mathrm{g} / \mathrm{dl}$ & $8.7 \pm 7.0$ \\
\hline HOMA-R & $2.9 \pm 2.7$ \\
\hline $\mathrm{hsCRP}, \mathrm{mg} / \mathrm{dl}$ & $0.190 \pm 0.357$ \\
\hline NT-proBNP, pg/ml & $36.2 \pm 55.3$ \\
\hline CPR, mg/dl & $2.8 \pm 9.6$ \\
\hline \multicolumn{2}{|l|}{ Fat areas determined by $C T$ scan } \\
\hline Total adipose tissue/BSA, $\mathrm{cm}^{2} / \mathrm{m}^{2}$ & $169.4 \pm 74.9$ \\
\hline Visceral adipose tissue/BSA, $\mathrm{cm}^{2} / \mathrm{m}^{2}$ & $68.3 \pm 30.6$ \\
\hline Subcutaneous adipose tissue/BSA, $\mathrm{cm}^{2} / \mathrm{m}^{2}$ & $101.1 \pm 54.3$ \\
\hline \multicolumn{2}{|c|}{$\begin{array}{l}\text { eGFR, estimated glomerular filtration rate; } H D L \text {, high-density lipoprotein; } F-L D L \text {, } \\
\text { low-density lipoprotein calculated by Friedewald; } N E F A \text {, non-esterified fatty } \\
\text { acid; } I R I \text {, immunoreactive insulin; } H O M A \text {, homeostasis model assessment; } \\
\text { hsCRP, high-sensitivity } C \text { reactive protein; } N T \text {-pro } B N P, N \text {-terminal pro b-type } \\
\text { natriuretic peptide; } C P R, C \text {-peptide immunoreactivity; } C T \text {, computed } \\
\text { tomography; } B S A \text {, body surface area. }\end{array}$} \\
\hline
\end{tabular}

Visceral adipose tissue is an important functional organ which abundantly secretes adipocytokines [33]. In the lean state, small adipocytes efficiently store fatty acids as triglyceride and have the ability to inhibit the inflammatory state. In particular, high levels of adiponectin in the lean state have anti-inflammatory effects [34]. On the other hand, increased visceral adipose tissue secrete various inflammatory cytokines, including tumor necrosis factor- $\alpha$ (TNF- $\alpha$ ), interleukin-6 (IL-6), IL-8 and MCP-1. These adipocytokines are assumed to contribute to changes in cardiac structure and function [22-24].

Increased inflammatory cytokines such as IL-6, IL-8 and MCP-1 have been shown to be significant indicators of a greater degree of heart failure with preserved EF [35]. High plasma levels of TNF- $\alpha$ and IL-6 might cause cardiac diastolic dysfunction by decreasing diastolic calcium reuptake in myocytes [36]. Studies in vitro showed that cardiac-restricted overexpression of TNF- $\alpha$ induces myocardial fibrosis and diastolic dysfunction [37]. Furthermore, low plasma adiponectin had an association with early diastolic dysfunction in patients with heart failure [24]. Taken together, these studies suggest that visceral fat accumulation may influence diastolic function through changes in inflammatory and anti-inflammatory adipocytokines. Furthermore, dysfunctional adipose tissue produces angiotensinogen and angiotensin II, which induces systemic hypertension [34]. In this study, $49 \%$ of patients in the diabetes mellitus group had hypertension. Although activation of the renin-angiotensin system in diabetes mellitus per se is associated with increased oxidative damage and cardiomyocyte apoptosis and necrosis in the diabetic heart [38], hypertension due to visceral adiposity may also influence diastolic function in T2DM. On the other hand, hsCRP, an inflammatory maker, was not directly related to cardiac dysfunction in the present study, whereas we found a significant correlation between hsCRP and VAT $(r=0.281, p<0.001)$. HsCRP can reflect inflammatory processes in various organs and is not only the mechanism by which VAT causes diastolic dysfunction. Presumably other inflammatory cytokines and anti- 
Table 4 Pearson's correlation between echocardiographic parameters and clinical data

\begin{tabular}{|c|c|c|c|c|c|c|c|c|c|c|}
\hline & \multicolumn{2}{|c|}{ LV mass index } & \multicolumn{2}{|c|}{ LA volume index } & \multicolumn{2}{|c|}{$\mathrm{E} / \mathrm{A}$} & \multicolumn{2}{|c|}{$\mathrm{e}^{\prime}$} & \multicolumn{2}{|c|}{$\mathrm{E} / \mathrm{e}^{\prime}$} \\
\hline & $r$ & $p$ & $r$ & $p$ & $r$ & $p$ & $r$ & $p$ & $r$ & $p$ \\
\hline Female gender & 0.050 & n.s. & -0.88 & 0.290 & -0.168 & 0.040 & -0.255 & 0.002 & 0.265 & 0.001 \\
\hline Age, year & 0.130 & n.s. & 0.235 & 0.004 & -0.495 & $<0.001$ & -0.464 & $<0.001$ & 0.300 & $<0.001$ \\
\hline Disease duration & 0.046 & n.s. & 0.206 & 0.012 & -0.167 & 0.041 & -0.190 & 0.021 & 0.076 & n.s. \\
\hline Systolic BP, mmHg & 0.202 & 0.013 & 0.123 & n.s. & -0.202 & 0.014 & -0.156 & n.s. & 0.103 & n.s. \\
\hline Diastolic BP, mmHg & 0.075 & n.s. & -0.119 & n.s. & 0.055 & n.s. & -0.036 & n.s. & -0.059 & n.s. \\
\hline Body mass index, $\mathrm{kg} / \mathrm{m}^{2}$ & 0.092 & n.s. & 0.060 & n.s. & 0.000 & n.s. & -0.064 & n.s. & 0.042 & n.s. \\
\hline Waist/Hip ratio & 0.173 & 0.035 & -0.003 & n.s. & -0.115 & n.s. & -0.114 & n.s. & 0.094 & n.s. \\
\hline Triglyceride, mg/dl & 0.084 & n.s. & -0.048 & n.s. & -0.056 & n.s. & -0.016 & n.s. & 0.090 & n.s. \\
\hline $\mathrm{HDL}$ cholesterol, mg/dl & -0.006 & n.s. & -0.143 & n.s. & 0.001 & n.s. & 0.071 & n.s. & 0.036 & n.s. \\
\hline F-LDL cholesterol, mg/dl & -0.187 & 0.022 & 0.012 & n.s. & 0.071 & n.s. & 0.064 & n.s. & -0.049 & n.s. \\
\hline Fasting plasma glucose, mg/dl & 0.007 & n.s. & -0.004 & n.s. & 0.074 & n.s. & -0.021 & n.s. & 0.127 & n.s. \\
\hline $\mathrm{HbA} 1 \mathrm{c}, \%$ & 0.037 & n.s. & 0.072 & n.s. & 0.061 & n.s. & 0.097 & n.s. & 0.063 & n.s. \\
\hline$|\mathrm{RI}, \mathrm{ug} / \mathrm{d}|$ & -0.111 & n.s. & -0.070 & n.s. & -0.011 & n.s. & -0.093 & n.s. & 0.043 & n.s. \\
\hline HOMA-R & -0.037 & n.s. & -0.057 & n.s. & 0.008 & n.s. & -0.121 & n.s. & 0.103 & n.s. \\
\hline eGFR, $\mathrm{ml} / \mathrm{min}$ & 0.015 & n.s. & -0.040 & n.s. & 0.310 & $<0.001$ & 0.266 & 0.001 & -0.092 & n.s. \\
\hline NEFA, $\mu \mathrm{Eq} / \mathrm{L}$ & -0.022 & n.s. & 0.086 & n.s. & 0.051 & n.s. & 0.075 & n.s. & -0.092 & n.s. \\
\hline hsCRP, mg/dl & -0.107 & n.s. & -0.143 & n.s. & 0.135 & n.s. & -0.028 & n.s. & 0.050 & n.s. \\
\hline Hypertensions & 0.105 & n.s. & 0.198 & 0.016 & -0.128 & n.s. & -0.340 & $<0.001$ & 0.218 & 0.008 \\
\hline VAT/BSA, $\mathrm{cm}^{2} / \mathrm{m}^{2}$ & 0.155 & n.s. & 0.197 & 0.016 & -0.205 & 0.012 & -0.320 & $<0.001$ & 0.217 & 0.008 \\
\hline $\mathrm{SAT} / \mathrm{BSA}, \mathrm{cm}^{2} / \mathrm{m}^{2}$ & 0.003 & n.s. & 0.114 & n.s. & -0.059 & n.s. & -0.177 & 0.031 & 0.186 & 0.023 \\
\hline VAT/SAT ratio & 0.164 & 0.045 & 0.022 & n.s. & -0.098 & n.s. & -0.087 & n.s. & -0.034 & n.s. \\
\hline
\end{tabular}

For abbreviations, see footnotes to Tables 1, 2 and 3.

inflammatory cytokines relate to visceral fat accumulation and are also significant determinant factors for cardiac dysfunction in T2DM.

Age-related decline in LV diastolic function even in a healthy population has been widely reported using conventional and tissue Doppler methods [18,19]. Gender differences in diastolic function have also been reported previously [19]. Epidemiological and clinical studies have consistently demonstrated that elderly women in the general population were most likely to have diastolic heart failure [39]. Menopausal hormone status has been suggested to be one of the factors to account for gender differences in diastolic dysfunction [40], although the precise mechanism has not been clarified.

As for LV hypertrophy, the waist/hip and VAT/SAT ratios were found to be independent determinants in

Table 5 Multivariate linear regression analysis between the echocardiographic parameters and clinical data

\begin{tabular}{|c|c|c|c|c|c|c|c|c|c|c|}
\hline & \multicolumn{2}{|c|}{ LV mass index } & \multicolumn{2}{|c|}{ LA volume index } & \multicolumn{2}{|c|}{$E / A$} & \multicolumn{2}{|c|}{$\mathrm{e}^{\prime}$} & \multicolumn{2}{|c|}{$E / e^{\prime}$} \\
\hline & $\beta$ & $p$ & $\bar{\beta}$ & $p$ & $\beta$ & $p$ & $\bar{\beta}$ & $p$ & $\beta$ & $p$ \\
\hline Female gender & & & & & & & -0.211 & 0.009 & 0.213 & 0.006 \\
\hline Age, year & & & 0.245 & 0.003 & -0.524 & $<0.001$ & -0.464 & $<0.001$ & 0.245 & $<0.002$ \\
\hline $\mathrm{sBP}, \mathrm{mmHg}$ & 0.205 & 0.013 & & & & & & & & \\
\hline Waist/Hip ratio & 0.173 & 0.024 & & & & & & & & \\
\hline \multicolumn{11}{|c|}{ F-LDL cholesterol, mg/dl } \\
\hline \multicolumn{11}{|l|}{ eGFR, $\mathrm{ml} / \mathrm{min}$} \\
\hline Hypertension & & & & & & & -0.324 & $<0.001$ & 0.199 & 0.006 \\
\hline $\mathrm{VAT} / \mathrm{BSA}, \mathrm{cm}^{2} / \mathrm{m}^{2}$ & & & 0.203 & 0.011 & -0.208 & 0.002 & -0.354 & $<0.001$ & 0.220 & 0.003 \\
\hline VAT/SAT ratio & 0.162 & 0.049 & & & & & & & & \\
\hline
\end{tabular}

For abbreviations, see footnotes on Tables 1, 2 and 3. 



Figure 2 Correlations between VAT and echo parameters (E/A, e', E/e', LA volume index). VAT was significantly correlated with these diastolic parameters. Pearson's correlation coefficients and significance are shown.

addition to systolic blood pressure. The waist/hip ratio, an indicator of obesity, was reported to be a predictor of cardiovascular mortality [41]. Abnormal fat distribution expressed as the VAT/SAT ratio was associated with the development of insulin resistance and atherosclerosis [42]. In this study, we could not determine the reason why the waist/hip and VAT/SAT ratios, but not the absolute amount of VAT, were independently related to increased LV mass. However, there is no doubt that visceral fat and obesity play some roles in the development of LV hypertrophy based on mechanisms similar to those of diastolic dysfunction in T2DM.

\section{Study limitations}

While we included asymptomatic patients without overt cardiovascular disease, we did not completely exclude latent patients with coronary artery disease using stress testing or coronary angiography. We did not measure serum adipocytokine levels and could not evaluate adipose dysfunction. Further investigation is required to determine the direct association between VAT and the level of adipocytokine dysfunction in diabetic cardiomyopathy. We included patients with the comorbidity of hypertension in this study. Hypertension caused by activation of the renin-angiotensin system in diabetes mellitus plays an important role in the development of cardiac dysfunction in T2DM. In addition, patients with T2DM have high prevalence of hypertension in the real clinical setting and are more subject to LV hypertrophy caused by hypertension than those without diabetes [43]. These characteristics are important aspects of cardiac dysfunction in T2DM. Instead, we performed multiple regression analysis using clinical factors including history of hypertension and blood pressure to evaluate the independent determinants of LV mass and diastolic dysfunction, and VAT or VAT/SAT ratio was an independent determinant of cardiac structure and function in our population after adjustment for history of hypertension and blood pressure. However, hypertension per se causes diastolic dysfunction and LV hypertrophy, and further investigation in normotensive patients with T2DM is desirable to more accurately assess the mechanisms of cardiac abnormalities in T2DM. Moreover, further investigation in comparison with patients with hypertension but without T2DM would provide new insights to this issue. Finally, we measured only LV ejection fraction as an indicator of systolic function in this study. Ernande et al [17]. reported reduced systolic strain using speckle-tracking imaging in T2DM; therefore, further investigation of systolic dysfunction with speckletracking imaging would be of interest.

\section{Conclusion}

This study confirms that diastolic dysfunction and LV hypertrophy are major characteristics of abnormal cardiac structure and function in T2DM. Among many clinical variables, excess VAT may play a significant role in the development of diastolic dysfunction and LV 
hypertrophy beyond glycemic control. Visceral fat accumulation would be a potential therapeutic target to improve cardiac dysfunction rather than glycemic control in T2DM.

\section{Competing interest}

There is no relationship with any industry.

\section{Authors' contributions}

$\mathrm{RI}$ and MD have designed this study in whole and drafted this manuscript. MM, SM, SC, TK and HS have contributed to design the echo part in this study and interpret its results. $\mathrm{Cl}$ and FS have contributed to design the visceral adipose tissue part in this study and interpret its results including laboratory data. HW has contributed to design this study in part and interpret the clinical data. TM has contributed to statistical analyses in this study. HD has revised this manuscript critically for important intellectual content and approved finally the manuscript submitted. All authors read and approved the final manuscript.

\section{Funding sources}

This work was partially supported by a Grant-in-Aid for Scientific Research C (24500554) from the Japan Society for the Promotion of Science (Masao Daimon).

\section{Author details}

'Department of Cardiovascular Medicine, Juntendo University School of Medicine, Tokyo, Japan. ${ }^{2}$ Department of Metabolism \& Endocrinology, Juntendo University School of Medicine, Hongo 2-1-1, Bunkyo-ku, Tokyo 113-8421, Japan.

Received: 19 December 2012 Accepted: 17 February 2013

Published: 27 February 2013

\section{References}

1. Boudina S, Abel ED: Diabetic cardiomyopathy revisited. Circulation 2007, 115:3213-3223.

2. Kannel WB, Hjortland M, Castelli WP: Role of diabetes in congestive heart failure: the Framingham study. Am J Cardiol 1974, 34:29-34.

3. Kannel WB, McGee DL: Diabetes and cardiovascular disease. The Framingham study. JAMA 1979, 241:2035-2038.

4. From AM, Scott CG, Chen HH: The development of heart failure in patients with diabetes mellitus and pre-clinical diastolic dysfunction a population-based study. J Am Coll Cardiol 2010, 55:300-305.

5. Liu JE, Palmieri V, Roman MJ, Bella JN, Fabsitz R, Howard BV, Devereux RB: The impact of diabetes on left ventricular filling pattern in normotensive and hypertensive adults: the Strong Heart Study. J Am Coll Cardiol 2001, 37:1943-1949.

6. Boyer JK, Thanigaraj S, Schechtman KB, Perez JE: Prevalence of ventricular diastolic dysfunction in asymptomatic, normotensive patients with diabetes mellitus. Am J Cardiol 2004, 93:870-875.

7. From $\mathrm{AM}, \mathrm{Scott} \mathrm{CG}$, Chen $\mathrm{HH}$ : Changes in diastolic dysfunction in diabetes mellitus over time. Am J Cardiol 2009, 103:1463-1466.

8. Schannwell CM, Schneppenheim M, Perings S, Plehn G, Strauer BE: Left ventricular diastolic dysfunction as an early manifestation of diabetic cardiomyopathy. Cardiology 2002, 98:33-39.

9. Severson DL: Diabetic cardiomyopathy: recent evidence from mouse models of type 1 and type 2 diabetes. Can J Physiol Pharmacol 2004, 82:813-823.

10. O'Neill BT, Abel ED: Akt1 in the cardiovascular system: friend or foe? J Clin Invest 2005, 115:2059-2064.

11. Poornima IG, Parikh P, Shannon RP: Diabetic cardiomyopathy: the search for a unifying hypothesis. Circ Res 2006, 98:596-605.

12. Westermann D, Walther T, Savvatis K, Sobirey M, Riad A, Bader M, Schultheiss HP, Tschöpe C: Gene deletion of the kinin receptor B1 attenuates cardiac inflammation and fibrosis during the development of experimental diabetic cardiomyopathy. Diabetes 2009, 58:1373-1381.

13. Gaikwad AB, Sayyed SG, Lichtnekert J, Tikoo K, Anders HJ: Renal failure increases cardiac histone h3 acetylation, dimethylation, and phosphorylation and the induction of cardiomyopathy-related genes in type 2 diabetes. Am J Pathol 2010, 176:1079-1083.
14. Rijzewijk LJ, van der Meer RW, Smit JW, Diamant M, Bax JJ, Hammer S, Romijn JA, de Roos A, Lamb HJ: Myocardial steatosis is an independent predictor of diastolic dysfunction in type 2 diabetes mellitus. J Am Coll Cardiol 2008, 52:1793-1799.

15. Di Bonito P, Moio N, Cavuto L, Covino G, Murena E, Scilla C, Turco S, Capaldo B, Sibilio G: Early detection of diabetic cardiomyopathy: usefulness of tissue Doppler imaging. Diabet Med 2005, 22:1720-1725.

16. Zarich SW, Arbuckle BE, Cohen LR, Roberts M, Nesto RW: Diastolic abnormalities in young asymptomatic diabetic patients assessed by pulsed Doppler echocardiography. J Am Coll Cardiol 1988, 12:114-120.

17. Ernande L, Bergerot C, Rietzschel ER, De Buyzere ML, Thibault H, Pignonblanc PG, Croisille P, Ovize M, Groisne L, Moulin P, Gillebert TC, Derumeaux G: Diastolic dysfunction in patients with type 2 diabetes mellitus: is it really the first marker of diabetic cardiomyopathy. J Am Soc Echocardiogr 2011, 24:1268-1275. e1.

18. Daimon M, Watanabe $H$, Abe $Y$, Hirata $K$, Hozumi T, Ishii K, Ito H, Iwakura $K$, Izumi C, Matsuzaki M, Minagoe S, Abe H, Murata K, Nakatani S, Negishi K, Yoshida K, Tanabe K, Tanaka N, Tokai K, Yoshikawa J: Normal values of echocardiographic parameters in relation to age in a healthy Japanese population: the JAMP study. Circ J 2008, 72:1859-1866.

19. Daimon $M$, Watanabe $H$, Abe $Y$, Hirata $K$, Hozumi $T$, Ishii $K$, Ito $H$, Iwakura $K$, Izumi C, Matsuzaki M, Minagoe S, Abe H, Murata K, Nakatani S, Negishi K, Yoshida K, Tanabe K, Tanaka N, Tokai K, Yoshikawa J: Gender differences in age-related changes in left and right ventricular geometries and functions. Echocardiography of a healthy subject group. Circ J 2011, 75:2840-2846.

20. Henkin L, Bergman RN, Bowden DW, Ellsworth DL, Haffner SM, Langefeld $C D$, Mitchell BD, Norris JM, Rewers M, Saad MF, Stamm E, Wagenknecht LE, Rich SS: Genetic epidemiology of insulin resistance and visceral adiposity. The IRAS Family Study design and methods. Ann Epidemiol 2003, 13:211-217.

21. Neeland IJ, Turer AT, Ayers CR, Powell-Wiley TM, Vega GL, Farzaneh-Far R, Grundy SM, Khera A, McGuire DK, de Lemos JA: Dysfunctional adiposity and the risk of prediabetes and type 2 diabetes in obese adults. JAMA 2012, 308:1150-1159.

22. Chen WJ, Rijzewijk LJ, van der Meer RW, Heymans MW, van Duinkerken E, Lubberink M, Lammertsma AA, Lamb HJ, de Roos A, Romijn JA, Smit JW, Bax JJ, Bjerre M, Frystyk J, Flyvbjerg A, Diamant M: Association of plasma osteoprotegerin and adiponectin with arterial function, cardiac function and metabolism in asymptomatic type 2 diabetic men. Cardiovasc Diabetol 2011, 10:67.

23. Solini A, Stea F, Santini E, Bruno RM, Duranti E, Taddei S, Ghiadoni L: Adipocytokine levels mark endothelial function in normotensive individuals. Cardiovasc Diabetol 2012, 11:103.

24. Negi SI, Jeong EM, Shukrullah I, Raicu M, Dudley SC Jr: Association of low plasma adiponectin with early diastolic dysfunction. Congest Heart Fail 2012, 18:187-191.

25. Lang RM, Bierig M, Devereux RB, Flachskampf FA, Foster E, Pellikka PA, Picard MH, Roman MJ, Seward J, Shanewise JS, Solomon SD, Spencer KT, Sutton MS, Stewart WJ: Recommendations for chamber quantification: a report from the American Society of Echocardiography's Guidelines and Standards Committee and the Chamber Quantification Writing Group, developed in conjunction with the European Association of Echocardiography, a branch of the European Society of Cardiology. J Am Soc Echocardiogr 2005, 18:1440-1463.

26. Nagueh SF, Appleton CP, Gillebert TC, Marino PN, Oh JK, Smiseth OA, Waggoner AD, Flachskampf FA, Pellikka PA, Evangelista A:

Recommendations for the evaluation of left ventricular diastolic function by echocardiography. J Am Soc Echocardiogr 2009, 22:107-133.

27. Canepa M, Strait JB, Abramov D, Milaneschi Y, AlGhatrif M, Moni M: Contribution of central adiposity to left ventricular diastolic function (from the Baltimore Longitudinal Study of Aging). Am J Cardiol 2012, 109:1171-1178.

28. Matthews DR, Hosker JP, Rudenski AS, Naylor BA, Treacher DF, Turner RC Homeostasis model assessment: insulin resistance and beta-cell function from fasting plasma glucose and insulin concentrations in man. Diabetologia 1985, 28:412-419.

29. Matsuo S, Imai E, Horio M, Yasuda Y, Tomita K, Nitta K, Yamagata K, Tomino Y, Yokoyama H, Hishida A: Revised equations for Eestimated GFR from serum creatinine in Japan. Am J Kidney Dis 2009, 53:982-992.

30. Kobayashi J, Tadokoro N, Watanabe M, Shinomiya M: A novel method of measuring intra-abdominal fat volume using helical computed tomography. Int J Obes Relat Metab Disord 2002, 26:398-402. 
31. Hemmingsen B, Lund SS, Gluud C, Vaag A, Almdal T, Hemmingsen C, Wetterslev J: Intensive glycaemic control for patients with type 2 diabetes: systematic review with meta-analysis and trial sequential analysis of randomised clinical trials. BMJ 2011, 343:d6898.

32. Boussageon R, Bejan-Angoulvant T, Saadatian-Elahi M, Lafont S, Bergeonneau C, Kassaï B, Erpeldinger S, Wright JM, Gueyffier F, Cornu C: Effect of intensive glucose lowering treatment on all cause mortality, cardiovascular death, and microvascular events in type 2 diabetes: metaanalysis of randomised controlled trials. BMJ 2011, 343:d4169.

33. Ryo M, Nakamura T, Kihara S, Kumada M, Shibazaki S, Takahashi M, Nagai M, Matsuzawa Y, Funahashi T: Adiponectin as a biomarker of the metabolic syndrome. Circ J 2004, 68:975-981.

34. Hajer GR, van Haeften TW, Visseren FL: Adipose tissue dysfunction in obesity, diabetes, and vascular diseases. Eur Heart J 2008, 29:2959-2971.

35. Collier P, Watson CJ, Voon V, Phelan D, Jan A, Mak G, Martos R, Baugh JA, Ledwidge MT, McDonald KM: Can emerging biomarkers of myocardial remodeling identify asymptomatic hypertensive patients at risk for diastolic dysfunction and diastolic heart failure? Eur J Heart Fail 2011, 13:1087-1095.

36. Zhang W, Chancey AL, Tzeng HP, Zhou Z, Lavine KJ, Gao F,

Sivasubramanian N, Barger PM, Mann DL: The development of myocardial fibrosis in transgenic mice with targeted overexpression of tumor necrosis factor requires mast cell-fibroblast interactions. Circulation 2011 , 124:2106-2116.

37. Wu CK, Lee JK, Chiang FT, Yang CH, Huang SW, Hwang JJ, Lin JL, Tseng CD, Chen JJ, Tsai CT: Plasma levels of tumor necrosis factor.alpha; and interleukin- 6 are associated with diastolic heart failure through downregulation of sarcoplasmic reticulum Ca2+ ATPase. Crit Care Med 2011, 39:984-992.

38. Dhalla NS, Liu X, Panagia V, Takeda N: Subcellular remodeling and heart dysfunction in chronic diabetes. Cardiovasc Res 1998, 40:239-247.

39. Regitz-Zagrosek V, Oertelt-Prigione S, Seeland U, Hetzer R: Sex and gender differences in myocardial hypertrophy and heart failure. Circ J 2010, 74:1265-1273.

40. Ling S, Dai A, Dilley RJ, Jones M, Simpson E, Komesaroff PA, Sudhir K. Endogenous estrogen deficiency reduces proliferation and enhances apoptosis-related death in vascular smooth muscle cells: insights from the aromatase-knockout mouse. Circulation 2004, 109:537-543.

41. Czernichow S, Kengne AP, Stamatakis E, Hamer M, Batty GD: Body mass index, waist circumference and waist-hip ratio: which is the better discriminator of cardiovascular disease mortality risk? Evidence from an individual-participant meta-analysis of 82864 participants from nine cohort studies. Obes Rev 2011, 12(201):680-687.

42. Yamashita S, Nakamura T, Shimomura I, Nishida M, Yoshida S, Kotani K, Kameda-Takemuara K, Tokunaga K, Matsuzawa Y: Insulin resistance and body fat distribution. Diabetes Care 1996, 19:287-291.

43. Palmieri V, Bella JN, Arnett DK, Liu JE, Oberman A, Schuck MY, Kitzman DW, Hopkins PN, Morgan D, Rao DC, Devereux RB: Effect of type 2 diabetes mellitus on left ventricular geometry and systolic function in hypertensive subjects: Hypertension Genetic Epidemiology Network (HyperGEN) study. Circulation 2001, 103:102-107.

\section{doi:10.1186/1475-2840-12-38}

Cite this article as: Ichikawa et al.: Influencing factors on cardiac structure and function beyond glycemic control in patients with type 2 diabetes mellitus. Cardiovascular Diabetology 2013 12:38.

\section{Submit your next manuscript to BioMed Central and take full advantage of:}

- Convenient online submission

- Thorough peer review

- No space constraints or color figure charges

- Immediate publication on acceptance

- Inclusion in PubMed, CAS, Scopus and Google Scholar

- Research which is freely available for redistribution

Submit your manuscript at www.biomedcentral.com/submit
( Biomed Central 